Nevşehir Bilim ve Teknoloji Dergisi Cilt 6(2) 681-689 2017

DOI: 10.17100/nevbiltek.334625

URL: http://dx.doi.org/10.17100/nevbiltek.334625

\title{
Bedensel Engelli Bireylerin Erişilebilir Turizmi Değerlendirmesi Üzerine Bir
}

\section{Araștırma}

\author{
Anıl EVCİ, Candan KUŞ ŞAHIN* \\ Süleyman Demirel Üniversitesi, Mimarlık Fakültesi, Peyzaj Mimarlı̆̆ı Bölümü, Isparta
}

Öz

Yaşamlarını geçici ya da kalıcı herhangi bir tür engellilik ile sürdürmek zorunda kalan insanlara hizmet sunmayı hedefleyen erişilebilir turizm, engellileri toplumdan dışlamayı değil, topluma katmayı öngörmektedir. Erişilebilir turizm; tüm insanların kısıtlı fiziksel hareket kabiliyetine sahip olup olmadıklarına bakılmaksızın, sürdürülebilir hizmet sunma ve beklentilerin karşılanması çabasıdır. Turizm sektöründe engelli bireylerin, ihtiyaç ve beklentilerinin anlaşılması, ulaşım, tesis ve hizmet sunumu imkânlarının oluşturulması, engellilerin turizm faaliyetlerine katılımlarını artırabilmektedir.

Bu çalışmada; engellilerin, Göreme Açık Hava Müzesi’ndeki engelli erişilebilirliği ile ilgili genel değerlendirilme yapmaları hedeflenmiştir. Bu bağlamda, ilgili kamu ve sivil toplum kuruluşları yöneticileri ile görüşülerek engellilerin beklentilerine ilişkin görüşlere ulaşma konusunda bilgiler edinilmiştir. Çalışmanın sonunda, engelli bireylerin turizm faaliyetine katılmasına engel olan koşullar tespit edilerek çözüm önerileri sunulmuştur.

Anahtar Kelimeler: Turizm, Engelli, Erişilebilir turizm, Göreme Açık Hava Müzesi

\section{A Research on Assessment of Accessible Tourism by Physically Handicapped Individuals}

\begin{abstract}
Accessible tourism, which aims to provide services to temporary or permanent physically handicapped people in order to foresight them in social inclusions. Accessible tourism, regardless of whether all people have limited physical mobility, it is an effort to provide sustainable service and meet expectations. In this sense, understanding of the needs and expectations of disabled people in the tourism activities and the provision of suitable facilities with appropriate services could be positively impact on participation of those people in tourism activities.

In this study; it was aimed to study and make an evaluation on the tourism services for the disabled people who has visited in Goreme Open Air Museum where located in Nevsehir province, Turkey. In this context, some interviews were conducted with relevant authorizes with public and non-governmental organizations for obtaining information on that area. Thereby, the detailed information's was collected and expectations were recorded for accessibility of those areas. At the end of the study, the current status of the area was determined and some opinions and suggestions have been issued for disabled people in order to easy accessibility on tourism activities.
\end{abstract}

Keywords: Tourism, Handicapped, Accessible tourism, Göreme Open Air Museum

\footnotetext{
*e-mail: candansahin@sdu.edu.tr
} 
Evci A., Kuş Şahin C.

\section{Giriş}

Günümüzün en büyük endüstrisi olarak kabul gören turizm, önümüzdeki yüzyılda daha da büyük olacağ 1 tahmin edilen bir sektördür [1]. Turizm, gelişmiş ve gelişmekte olan ülkelerin gayri safi milli hasılalarının büyük bir bölümünü oluşturan hizmet sektörünün en önemli payını teşkil etmektedir. $\mathrm{Bu}$ nedenle, dünya üzerinde çekici olduğu düşünülen özelliklere sahip her yerde, bu sektöre yönelik politikalar üretilmektedir [2]. Engelli turizmi de bu politikalardan birisi olup zaman içerisinde evrimleşerek erişilebilir turizm haline dönüşmüştür.

Engelliyi tanımlamak üzere gerek yazın dilinde gerekse konuşma dilinde çok farklı ifadeler kullanılmakta (engelli, özürlü, sakat vb.) ve bu konuda kavram karmaşası yaşanmaktadır. Son yıllarda yasal tanımlamalarda, kanunlarda, medyada ve bilimsel çalışmalarda "engelli" kelimesi tercih edilmekte, "özürlü, sakat, güçsüz" gibi tabirler kaba bir ifade olarak ele alınmaktadır [3]. Engel-özür kavramı; "bireyin yaşadığı sürece yaş, cinsiyet sosyal ve kültürel faktörlere bağlı olarak toplumda oynaması gereken rolleri yetersizlik yüzünden yerine getirememesi durumudur” şeklinde tanımlanmaktadır [4]. Yani birey belirli bir zamanda, belirli bir durumda yapmak istediklerini yetersizlik yüzünden başaramazsa, yetersizlik özür veya engele dönüşmektedir.

Tanımların ve kavramların kapsamları, engele bakış açısını göstermek bakımından oldukça önemlidir. Çünkü engellilik, kentsel tasarımda yapılan uygulamalara yansımakta, engelliye uygulanan hak ve hizmetlerin boyutunu ortaya çıkarmaktadır. Bu nedenle, engelliliğe dair terminoloji oldukça çeşitlidir. Engelliliğin tanımı ve kapsam alanı ülkelere göre de değişiklik göstermektedir [5,6].

Engelliler için yapılan her türlü iyileştirme ve düzenlemeler; hamileler, bebek arabalılar, çocuklar, yaşlılar, çok kısa ve çok uzun boylu kişiler, eşya taşıyanlar gibi hareket kısıtll1lı̆ı olduğu için yapılı çevreyi kullanırken zorluk yaşayan veya hiç kullanamayan kişiler için de bir gerekliliktir. Ayrıca sağlıklı ve erişim sıkıntısı olmayan bireylerin de zaman zaman görme, duyma, algılama, işitme vb. boyutlu erişimde sıkıntılar yaşadığı ve eksikliklerinin olduğu görülmektedir. Bu kapsamda erişilebilirlik, ulaşlabilirlik, sirkülasyon gibi kavramlar önem arz etmektedir [3].

Erişilebilirlik; "farklı kişisel özellikleri bulunan insanların bağımsız olarak kendilerine sunulan tüm olanaklara, fiziksel ve sosyal olarak yaratılan etkinliklere ve donatılara ulaşabilmesi ve burayı kullanabilmesidir" [6]. Toplum hayatına gerek katılımda gerekse ihtiyaçlar doğrultusunda mekana ulaşmak ve ulaşılan bu mekanı kullanabilmek oldukça önemlidir. Herkes bu mekanlardan bağımsız ve eşit olarak faydalanma hakkına sahiptir.

Göreme Tarihi Milli Parkı içerisinde yer alan Göreme Açık Hava Müzesi, konum olarak Kapadokya bölgesindeki tarihi doğal yapıların en korunaklı şekilde olduğu ve turizm faaliyetleri açısından en fazla turist çeken yerlerinden birisidir [3]. Göreme Açık Hava Müzesi, 2015 yılında yaklaşık 975.000 ziyaretçisi ile ülkemizin en fazla ziyaret edilen altıncı müze-ören yeridir [7]. Bu açıdan bakıldığında, Göreme Açık Hava Müzesi’nde sirkülasyonun çok yoğun olduğu görülmektedir. Bu nedenle, alan içerisinde turizm faaliyetlerinin uygun bir şekilde yürümesi için sağlıklı bireyler kadar özel erişim ihtiyacı olan bireyler için de uygun mekan konforunun sağlanması gerekmektedir. 


\section{Materyal ve Metot}

\subsection{Materyal}

Çalışmanın ana materyalini Göreme Açık Hava Müzesi oluşturmaktadır (Şekil 1).

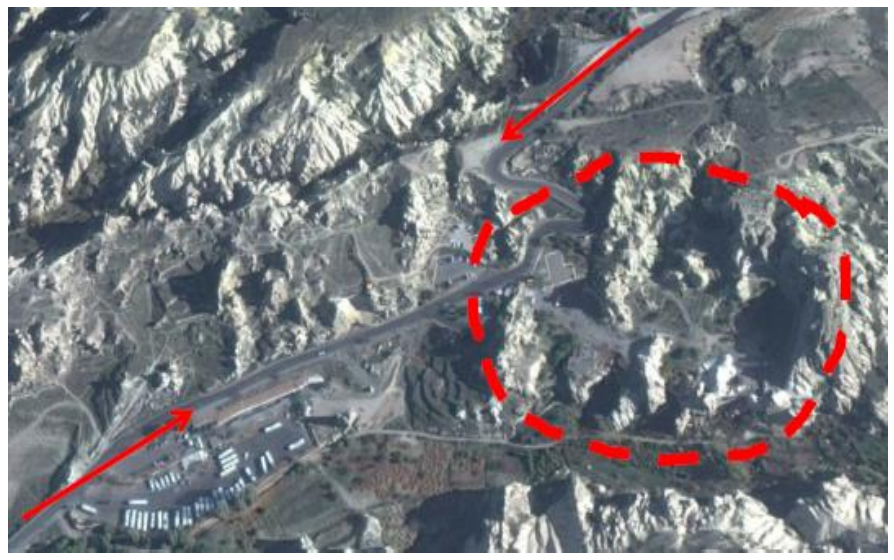

Şekil 1. Göreme Açık Hava Müzesi’nin konumu [3]

Nevşehir'e 13 km uzaklıkta ve Göreme kasabasının 2 km doğusunda yer alan bir kaya yerleşim yeri olan Göreme Açık Hava Müzesi, manastır eğitim sisteminin başlatıldığg yer olarak kabul edilmektedir (Şekil 2). Alanda, MS 4. yüzyıldan 13. yüzyıla kadar yoğun bir şekilde manastır hayatı yaşanmıştır. Hemen her kaya bloğunun içinde kiliseler, şapeller, yemekhaneler ve oturma mekânları mevcuttur [8].

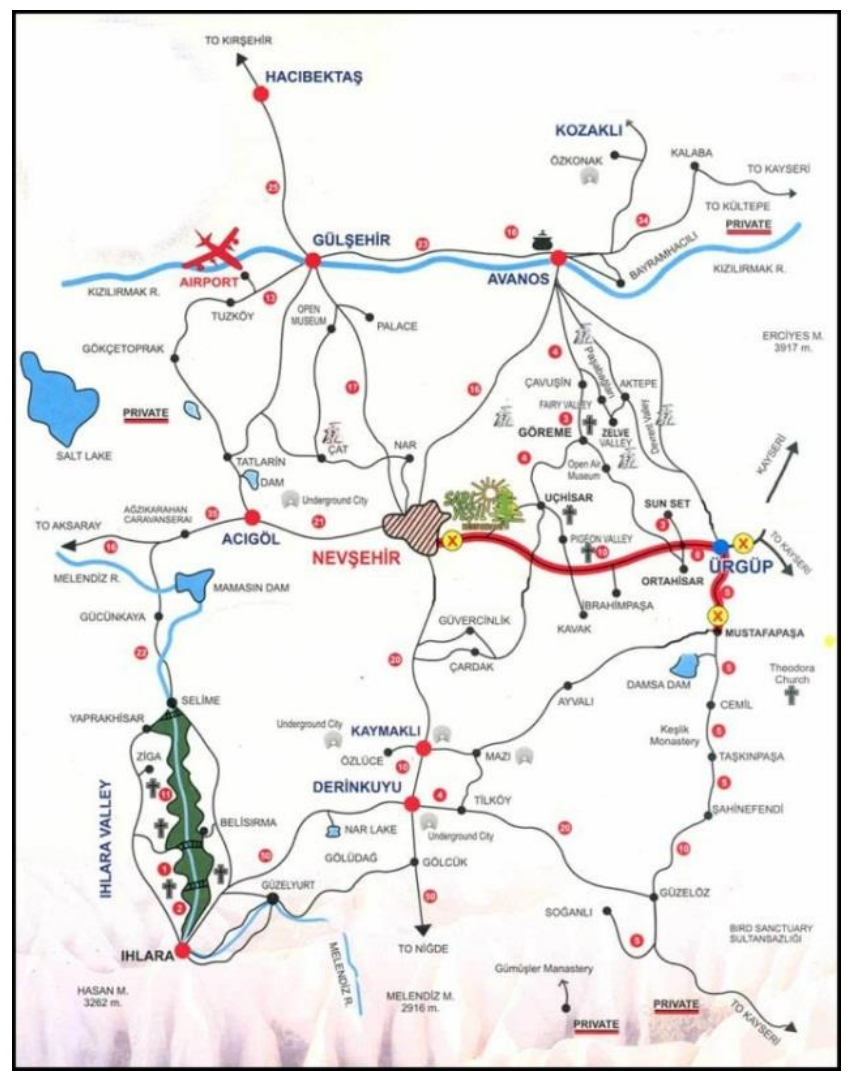

Şekil 2. Çalışma alanı yakın çevre haritası [9] 
Karasal iklimin görüldüğü bölgede, karasal volkanik formasyonlara bağlı olarak az killi, kumlu, tüflü ve nemsiz topraklar oluşmuştur. Bağcılık ve meyveciliğe çok elverişli olan bu topraklar, sulu tarıma elverişli değildir. İlkbaharda yeşeren yaz mevsiminde sararıp yok olan step bitki formasyonu tüm bölgede yayılış göstermektedir [10]. Turizm mevsimi Mayıs-Kasım ayları arasında maksimum altı aylık bir süreci kapsamaktadır. Toplam 40 da $\left(40.000 \mathrm{~m}^{2}\right)$ alana sahip olan Göreme Açık Hava Müzesi, oldukça engebeli bir yapıdadir.

\subsection{Metot}

Yapılan çalışmada Göreme Açık Hava Müzesi’nde erişilebilirlik konusunda bedensel engelli bireylerin görüşleri alınmıştır. Bunun için, Nevşehir Engelliler Derneği ve bazı kamu kuruluşlarıyla görüşmeler yapılmış ve çeşitli kurum ve pozisyonlarda görev yapan, emekli olan ve çalışmayan sekiz engelli birey ile röportaj gerçekleştirilmiştir.

Alana ulaşım ve yakın çevresi ile alan içerisindeki mevcut yapılar ve sirkülasyon verileri, alanda gerçekleştirilen gözlem ve veri toplama çalışmaları ile ortaya konulmuştur. Söz konusu bulgular sonucunda değerlendirmeler yapılarak önerilerde bulunulmuştur.

\section{Araştırma Bulguları}

\subsection{Alana Ulașım ve Yakın Çevresi}

Göreme kasabasının 2 km doğusunda yer alan Göreme Açık Hava Müzesi’ne ulaşım, Göreme merkezinden ve Ortahisar-Ürgüp yolundan sağlanmaktadır.

Açık Hava Müzesi'nin girişinde bir adet otobüsler için ve iki adet özel araçlar için olmak üzere toplam üç adet otopark bulunmaktadır. Müze girişinde, yöreye özgü dergi ve broşürlerin satıldığı seyyar tezgahlar yer almaktadır. Ayrıca bu noktalarda idari ofisler ve bilet satış noktaları da mevcuttur. Alana iki farklı giriş söz konusudur. Birincisi bilet ofísinden bilet alınarak yapılan giriş, diğeri ise müze kart sistemiyle doğrudan turnike geçişi şeklindedir (Şekil 3).
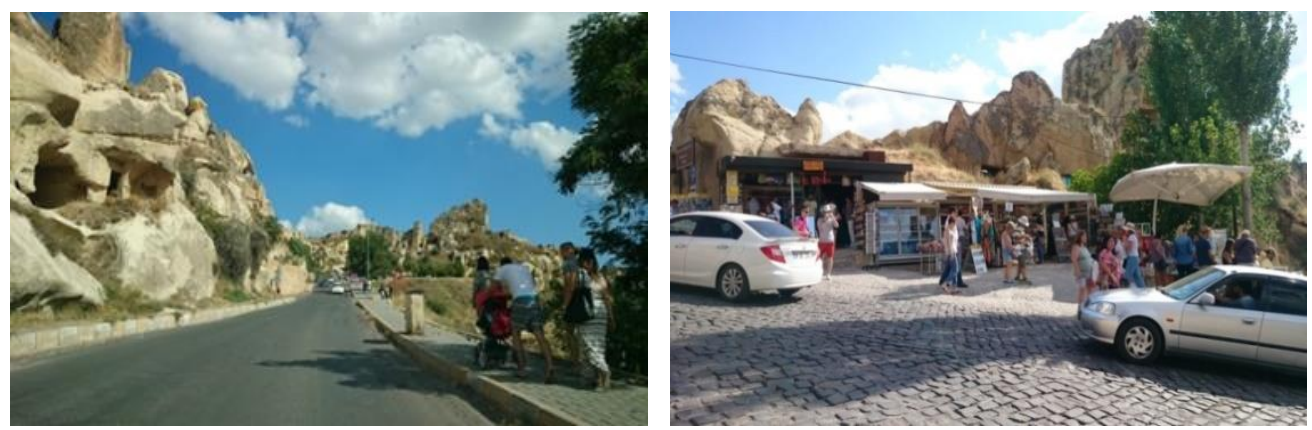

Şekil 3. Göreme Açık Hava Müzesi ulaşım hattı ve yakın çevresi [3]

\subsection{Alan İçerisindeki Mevcut Yapılar ve Sirkülasyon}

Göreme Açık Hava Müzesi içerisinde; Kızlar Manastırı, Aziz Basil Kilisesi, Elmalı Kilise, Azize Barbara Kilisesi, Yılanlı Kilise, Yemekhane, Karanlık Kilise, Azize Katarina Kilisesi ve Çarıklı Kilise olmak üzere dokuz adet kilise bulunmaktadır. Kiliselerin konumları Şekil 4'te yer almaktadır. 


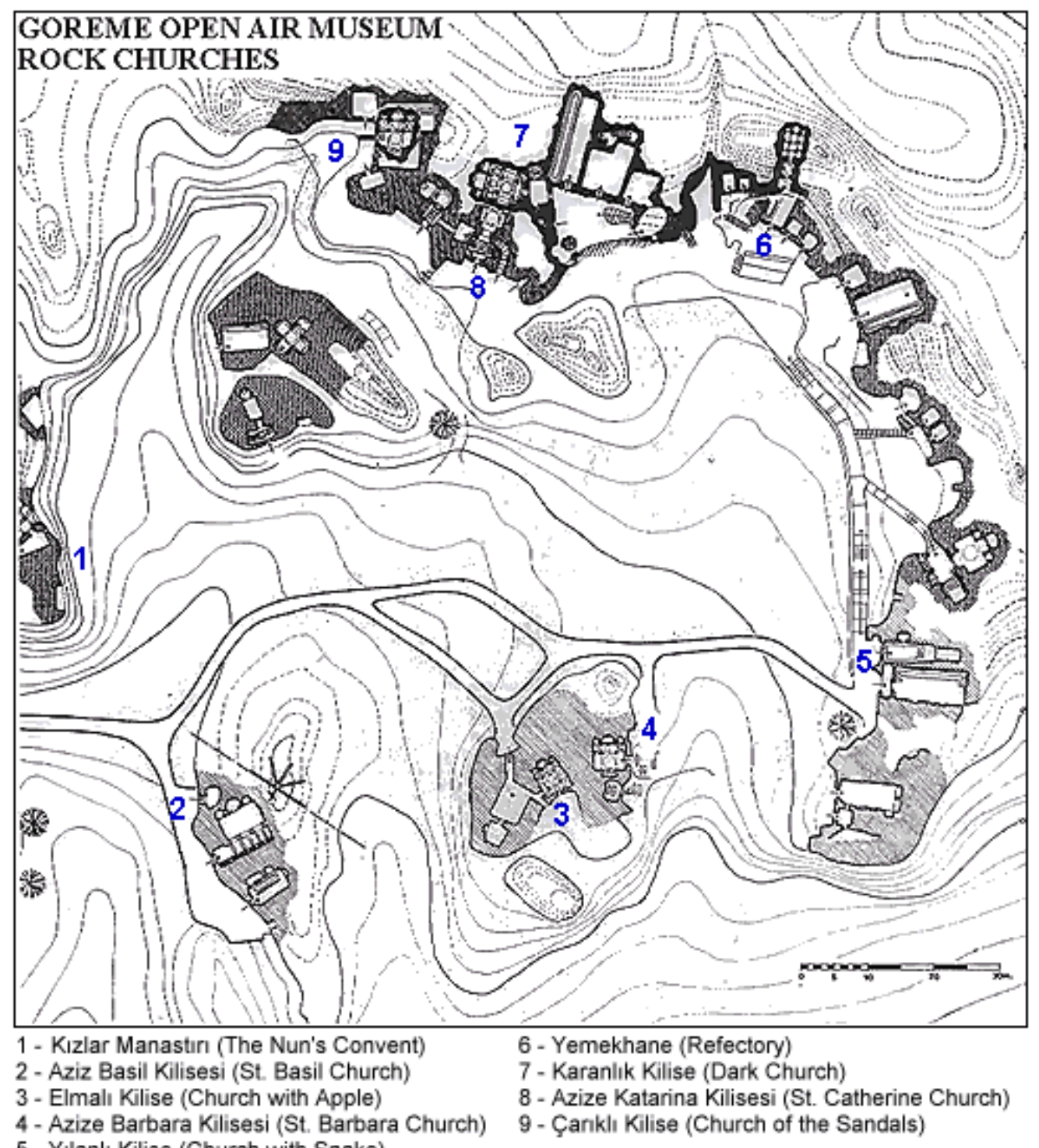

5 - Yılanlı Kilise (Church with Snake)

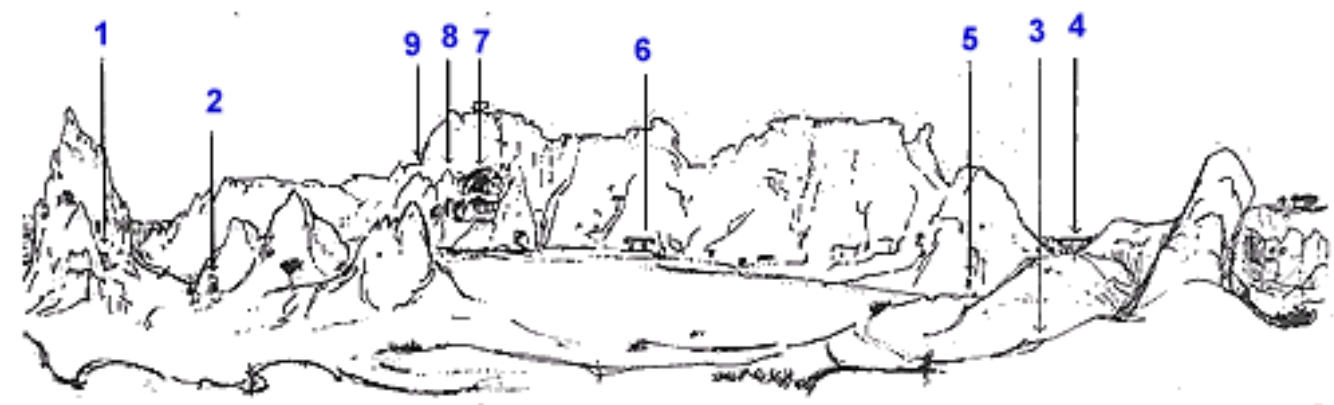

Şekil 4. Göreme Açık Hava Müzesi içindeki mevcut yapıların konumu ve sirkülasyonu [9]

Göreme Açık Hava Müzesi’ne girildikten sonra geniş bir toplanma alanı bulunmaktadır. Genellikle tur şirketiyle gelen turistler, müze ziyareti sonunda burada toplanmakta ve buradan tur otobüslerine geçmektedirler. Ayrıca burada bir de kitap standı yer almaktadır. Turnike girişlerinin yanında, hediyelik eşyaların satıldığı ve dinlenme amaçlı yapılmış, hem açık hem de kapalı alana sahip kafeterya bulunmaktadır. $\mathrm{Bu}$ alan, turistler tarafından müze giriş ve çıkışlarında yoğun olarak kullanılmaktadır. Toplanma alanında ayrıca tuvaletler mevcut olup bir adet de engelli tuvaleti bulunmaktadır. Ancak bakımsız ve atıl durumda olduğu için kullanılmamaktadır. 
Toplanma alanından güney yönüne doğru ilerlendiğinde, yol iki aksa ayrılmaktadır. Güneybatı yönüne ayrılan yol, Aziz Basil Kilisesi’ne gitmektedir. Aziz Basil Kilisesi’nin bulunduğu yer, vadi yamacına bakmaktadır. Buradan geniş vadi manzaralarını ve güvercinlikleri izlemek mümkündür. İki kola ayrılan aksın güneydoğu yönüne ilerlendiğinde, hafif rampalı yoldan Elmalı Kilise’ye ulaşılmaktadır. Azize Barbara Kilisesi ise Elmalı Kilise'nin bulunduğu kaya bloğun arkasında yer almaktadır (Şekil 5). Azize Barbara Kilisesi Göreme Açık Hava Müzesi içerisindeki en ilginç görünümlü kiliselerden birisidir.

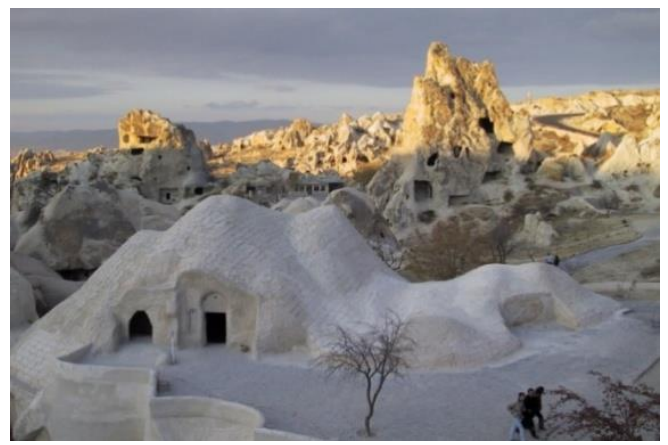

Şekil 5. Azize Barbara Kilisesi [3]

Azize Barbara Kilisesi’nin çıkışından itibaren devam eden eğimli yolun karşısında, Yılanlı Kilise bulunmaktadır. Azize Barbara Kilisesi ve Yılanlı Kilise arasında devam eden yolun yan tarafinda geniş bir dinlenme alanı bulunmaktadır. Dinlenme alanında, gölgelikler ve oturma birimleri mevcuttur. Yılanlı kiliseden sonra devam eden aksta yüksek yol eğimleri başlamaktadır.

$\mathrm{Bu}$ aks üzerinde bazı noktalarda merdivenli ve rampalı çözümler mevcuttur. Yol üzerinde Yemekhane bölümü ve sonrasında Karanlık Kilise bulunmaktadır. Karanlık Kilise, Göreme Açık Hava Müzesi içerisindeki en korunaklı kilise olup diğer kiliselerden farklı olarak giriş için ücret talep edilmektedir. Karanlık Kilise avlusundan, müze ve alt tarafındaki vadi oldukça panoramik bir şekilde görülmektedir (Şekil 6).
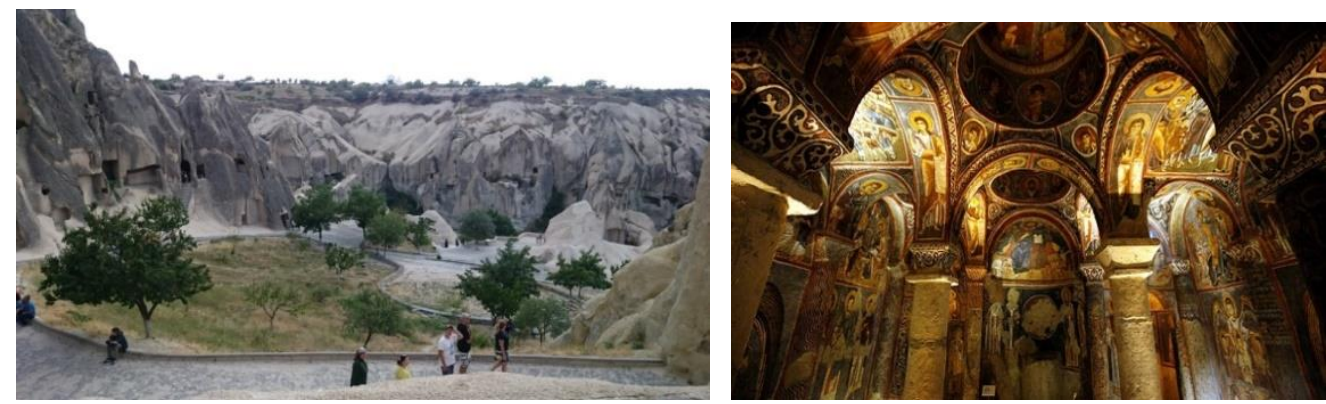

Şekil 6. Karanlık Kilise ve geniș müze manzarası [3]

Azize Katarina Kilisesi, Karanlık Kilise ile Çarıklı Kilise arasında yer almaktadır. Azize Katarina Kilisesi’nden sonra müzenin zirve noktasında bulunan Çarıklı Kilise’ye ulaşılmaktadır. Müzenin en yüksek noktası burası olup bu noktadan sonra iniş aksı başlamaktadır. Merdivenlerin en yoğun kullanımı iniş aksı üzerindedir (Şekil 7). 

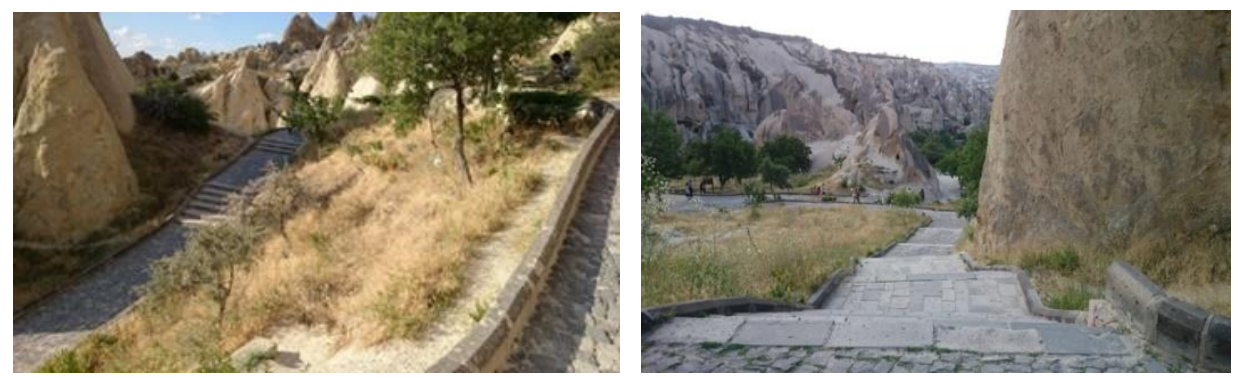

Şekil 7. İniş aksı [3]

İniş aksının sonunda yeniden toplanma alanına ulaşılmaktadır ve bu noktada da Kızlar Manastırı bulunmaktadır. Kızlar Manastırı yıkılma tehlikesi ile karşı karşıya olduğundan ziyaretine izin verilmemektedir ve mühürlü durumdadır.

\subsection{Engellilere İlişskin Röportaj (Mülakat) Süreci}

\subsubsection{Katılımcıların Kişisel Özellikleri}

Göreme Açık Hava Müzesi’nde, erişilebilirlik konusunda bedensel engelli bireylerin görüşlerinin alınması amacıyla gerçekleştirilen röportaja, yedi erkek ve bir bayan olmak üzere toplam sekiz birey katılmıştır. Bireylerin yaş aralıkları incelendiğinde; 30-39 yaş aralığında dört kişinin, 40-49 yaş aralığında iki kişinin ve 60 yaşın üstünde de iki kişinin olduğu görülmektedir. Röportaja katılan tüm bireyler Nevşehir'de ikamet etmektedirler.

Röportaja katılan bireylerin tamamı bedensel engellidir. Bu bireylerden iki tanesi doğuştan, altı tanesi ise sonradan bedensel engelli olduğunu belirtmiştir. Sonradan engelli olan bireylerin üç tanesi hastalık sebebiyle, iki tanesi trafik kazasından dolayı ve bir tanesi de iş kazası sonucunda bedensel engelli olmuştur. Bedensel engelli olan bireylerin tamamı tekerlekli sandalye kullanmaktadır.

\subsubsection{Engelli Bireylerin Değerlendirmeleri}

Erişilebilirlik konusunda, engelli bireylerin görüşlerinin alınması için bedensel engelli bireyler ile görüşülmüştür. Görüşmelere katılan bedensel engelli bireylerin tamamı, evlerinden sokağa rahat olarak çıkabildiklerini ancak engelliler için özel olarak tasarlanmış mekanlardan ziyade herkesin yararlanabileceği ortak kullanım alanlarının olması gerektiğini ifade etmişlerdir.

Doğuştan engelli olan bireylere Göreme Açık Hava Müzesi ile ilgili ziyaretleri sorulduğunda, sadece bir kere gittiklerini ifade etmişlerdir. Ulaşımda yaşanan sıkıntılar nedeniyle özel araçları ile alana giden bireyler, alanın engebeli yapısı ve engellilere yönelik gereksinimlerin karşılanamaması nedeniyle, alanı sınırlı olarak gezebildiklerini belirtmişlerdir. Sonradan engelli olan bireylerin Göreme Açık Hava Müzesi'ni ziyaretleri sorulduğunda, engelli olduktan sonra alana gitmedikleri ifade edilmiştir. Bunun sebebi olarak; alanın engebeli olduğu, alanda yer alan rampaların eğimlerinin fazla genişliklerinin ise az olduğu, alanda çok fazla merdiven olduğu ve zemin yapısının uygun olmadığı belirtilmiştir. Bireyler alanı en son, engelli olmadan önce görmüşlerdir.

Engelli bireylere alan içi ulaşımın uygunluğu sorulduğunda; engellilerden altısı, alan içi ulaşımları yetersiz bulmakta, ikisi ise kısmen yeterli bulmaktadır. Alan içerisindeki en büyük 
eksikliklerin; aydınlatma elemanlarının, bitkisel materyallerin ve yönlendirici yol işaretlerinin yetersizliği olduğu ifade edilmiştir.

Alana gittikleri için memnun kaldıklarını belirten engelli bireyler, tekrar gitmek istediklerini ifade etmişlerdir. Ancak, bedensel engellerinin devam etmesi ve tekerlekli sandalye kullanmaları nedeniyle bunun mümkün olmayacağını belirtmişlerdir.

\section{Sonuç ve Öneriler}

Görüşmelere katılan bedensel engelli bireylerin ifadeleri değerlendirildiğinde, Göreme Açık Hava Müzesi’nin engelliler açısından daha erişilebilir hale getirilmesi için alınması gereken önlemler ve geliştirilmesi gereken stratejiler aşağıdaki şekilde sıralanabilir:

- Alana ulaşım tekrar ele alınmalıdır. Özellikle toplu taşıma araçları çoğaltılmalıdır.

- Alan içerisinde engelli parkurları oluşturulmalıdır.

- Alan içerisinde gezinti araçları olmalı ve engelli bireyler bu araçlardan yararlanmalıdır.

- Engelliler için atv turları düzenlenmelidir.

- Kilise girişlerindeki tehlikeler en aza indirilmelidir.

- Alanda çevre düzenlemesi yapılarak, alanın daha kullanışlı hale getirilmesi gerekmektedir.

- Alan içerisinde engelli bireyleri taşıyacak (merdiven yerine geçebilecek) asansörlü sistem yapilmalıdır.

- Alan içinde engellilere yönelik rehberlik hizmetleri artırılmalıdır.

- Gerekli incelemeler yapılarak, alanın Türkiye ve Avrupa tarafından kabul edilen erişim standartlarına uygun hale getirmesi sağlanmalıdır.

- Genel anlamda engellilere yönelik ilgisizlik kırılmalı ve herkesin bir gün engelli olabileceği gerçeği göz ardı edilmemelidir.

Turizm faaliyetleri, genellikle engeli olmayan, sağlıklı bireylere göre tasarlanmakta ve uygulanmaktadır. Fakat söz konusu faaliyetlere katılmak, engelli bireylerin de hakkıdır. Bu bağlamda turizm faaliyetlerinin bütün bireylerin ihtiyaçlarını karşılayacak şekilde düzenlenmesi gerekmektedir. Erişilebilir turizm kavramı doğrultusunda, Göreme Açık Hava Müzesi'nde de mevcut olan kullanımlar revize edilerek, herkes için kullanılabilir ve erişilebilir hale getirilmelidir.

\section{Teşekkür}

Bu makale 15-17 Mayıs 2017 tarihinde düzenlenen International Conference on Agriculture, Forest, Food Sciences and Technologies (ICAFOF 2017 Cappadocia / Turkey) konferansında sözlü bildiri olarak sunulmuş ve bildiri özetleri kitabında yayınlanmıştır (s.195).

\section{Kaynaklar}

[1] Cothran, D.A., Cothran, C.C., "Promise or Political Risk for Mexican Tourism" Annals of Tourism Research, 25(2), 477-497, 1998

[2] Olalı, H., "Turizm Politikası ve Planlanması" İstanbul Üniversitesi İşletme Fakültesi Yayınları, 462s, İstanbul, 1990 
[3] Evci, A., “Göreme Açık Hava Müzesi’nin Erişilebilir Turizm Açısından İrdelenmesi” Süleyman Demirel Üniversitesi, Fen Bilimleri Enstitüsü, Yüksek Lisans Tezi, 157s, Isparta, 2016

[4] Ayyıldız, T., Atay, H., Yazıcı, A., "Konaklama İşletmelerinin Engelliler İçin Olanakları ve Yöneticilerin Görüşleri: Kuşadası Örneği” Gazi Üniversitesi Turizm Fakültesi Dergisi, 2, 84100,2014

[5] Uslu, A., “Kentsel Tasarımda Engelli Dostu Yaklaşımı” Engelli Dostu Belediye Sempozyumu, 58-77, Ankara, 27 Mayıs 2008

[6] Çınar, N., "Üniversite Kampüslerindeki Peyzaj Erişilebilirliğinin Engelliler Açısından İrdelenmesi” Ankara Üniversitesi, Fen Bilimleri Enstitüsü, Yüksek Lisans Tezi, 143s, Ankara, 2010

[7] Döner Sermaye İşletmesi Merkez Müdürlüğü (DÖSİMM), "Müze İstatistikleri” http://www.dosimm.gov.tr/muze-istatistikleri, Erişim Tarihi: 06.07.2016

[8] Nevşehir İl Kültür $\quad$ ve $\quad$ Turizm http://www.nevsehirkulturturizm.gov.tr/TR,74202/genel-bilgiler.html, Erişim Tarihi: 25.12.2015

[9] Anonim, 2016/h. http://www.balonturu.net/page/5?s=peri+bacalar\%C4\%B1, Erişim Tarihi: 15.07.2016

[10] Nevşehir Müze Müdürlüğü, Nevşehir Müze Müdürlüğü ile Yapılan Görüşme Verileri, 2016 